\title{
PENERAPAN STRATEGI PEMBELAJARAN INTERAKTIF DENGAN TEKNIK PEMBELAJARAN KOLABORATIF SEND-A-PROBLEM TERHADAP KEMAMPUAN PEMECAHAN MASALAH MATEMATIS SISWA KELAS IX SMP
}

\author{
Beni Junedi ${ }^{1}$, Juliana ${ }^{2}$ \\ ${ }^{1}$ Program Studi Pendidikan Matematika STKIP Insan Madani Airmolek. \\ ${ }^{2}$ Mahasiswa Program Studi Pendidikan Matematika STKIP Insan Madani Airmolek. \\ beni_junedi@yahoo.com ${ }^{1}$,juliana9420@yahoo.com ${ }^{2}$
}

\begin{abstract}
Mathematical problem solving is a process that includes understanding problems, planning problem solving, solving problems and checking again. Writing this article aims to determine the mathematical problem solving abilities of students by applying interactive learning strategies with collaborative learning techniques a-problem and conventional learning. This study was a quasi-experimental study with a randomized subject design posttest only control group design. Data collection techniques in the form of essay tests by testing hypotheses using the t-test. The results of the hypothesis test concluded that mathematical problem solving ability with the application of interactive learning strategies with collaborative learning technique is a problem better than conventional learning.
\end{abstract}

Keywords: Interactive Learning, Collaborative Techniques Send-a-Problem, Mathematical Problem Solving Ability

\begin{abstract}
Abstrak. Pemecahan masalah matematis merupakan suatu proses yang meliputi memahami masalah, merencanakan penyelesaian masalah, menyelesaikan masalah serta pengecekan kembali. Penulisan artikel ini bertujuan untuk mengetahui kemampuan pemecahan masalah matematis siswa dengan penerapan strategi pembelajaran interaktif dengan teknik pembelajaran kolaboratif send-a-problem dan pembelajaran konvensional. Penelitian ini merupakan penelitian eksperimen semu dengan rancangan randomized subject posttest only control group design. Teknik pengumpulan data berupa tes essay dengan pengujian hipotesis menggunakan uji-t. Hasil uji hipotesis disimpulkan bahwa kemampuan pemecahan masalah matematis dengan penerapan strategi pembelajaran interaktif dengan teknik pembelajaran kolaboratif send-a-problem lebih baik dari pada pembelajaran konvensional.
\end{abstract}

Kata Kunci: Pembelajaran Interaktif, Teknik Kolaboratif Send-a-Problem, Kemampuan Pemecahan Masalah Matematis

\section{PENDAHULUAN}

Pemecahan masalah adalah proses melibatkan suatu tugas yang metode pemecahannya belum diketahui terlebih dahulu, untuk mengetahui penyelesainnya siswa hendaknya memetakan pengetahuan mereka, dan melalui proses ini mereka sering mengembangkan pengetahuan baru tentang matematika.

Salah satu tujuan pembelajaran matematika agar peserta didik memiliki kemampuan pemecahan masalah yang meliputi kemampuan memahami masalah, merancang model matematika, menyelesaikan model dan menafsirkan solusi yang diperoleh (BSNP, 2006). Tujuan tersebut menempatkan pemecahan masalah menjadi bagian dari kurikulum matematika yang penting. Dalam proses pembelajaran maupun menyelesaikan masalah, siswa dapat memperoleh pengalaman menggunakan pengetahuan serta keterampilan yang sudah dimiliki. Pengalaman inilah yang kemudian melatih daya pikir siswa menjadi logis, analitis, sistematis, kritis dan kreatif dalam menghadapi persoalan.

Melalui latihan memecahkan masalah, siswa akan belajar mengorganisasikan kemampuannya dalam menyusun strategi yang sesuai untuk menyelesaikan masalah. Jika seorang siswa telah berlatih menyelesaikan masalah, maka dalam kehidupan nyata, siswa 
akan mampu mengambil keputusan terhadap suatu masalah, sebab siswa telah mempunyai keterampilan mengumpulkan informasi yang relevan, menganalisis informasi dan menyadari betapa perlunya meneliti kembali hasil yang telah diperoleh.

Berdasarkan hasil observasi, pembelajaraan yang sedang berlangsung masih didominasi oleh guru. Selama proses pembelajaran interaksi yang terjadi hanya satu arah yaitu dari guru ke siswa. Sehingga menyebabkan siswa kurang aktif serta minat dan motivasi siswa kurang dalam mengikuti pelajaran. Hal ini dikarenakan, siswa hanya mendengarkan dan menyalin apa yang dijelaskan guru dan siswa tidak memiliki peranan dalam proses pembelajaran. Dalam mengukur keaktifan siswa dapat dilihat dari berbagai hal seperti, memperhatikan (visual activities), mendengarkan, berdiskusi, kesiapan siswa, bertanya, keberanian siswa, mendengarkan, memecahkan soal (mental activities).

Kemampuan pemecahan masalah dapat dilihat dari proses dan hasil belajar. Berdasarkan data yang diperoleh dari guru matematika SMP Negeri 6 Rengat, hasil belajar matematika siswa kelas IX SMP Negeri 6 Rengat masih kurang memuaskan. Berdasarkan hasil ulangan matematika kelas IX SMP Negeri 6 Rengat yang dapat dilihat pada tabel 1 di bawah ini.

Tabel 1. Nilai Ulangan Harian Kelas IX SMP Negeri 6 Rengat

\begin{tabular}{|c|c|c|c|c|c|}
\hline \multirow{2}{*}{ Kelas } & \multirow{2}{*}{ Jumlah Siswa } & \multirow{2}{*}{ KKM } & \multicolumn{2}{|c|}{ Persen (\%) } & \multirow{2}{*}{ Rata-Rata $(\bar{x})$} \\
\hline & & & Tuntas & Tidak Tuntas & \\
\hline IXa & 28 & 60 & $53,57 \%$ & $46,43 \%$ & 49,25 \\
\hline IXb & 26 & 60 & $30,77 \%$ & $69,23 \%$ & 45,5769 \\
\hline
\end{tabular}

SMP Negeri 6 Rengat menetapkan nilai KKM 60 untuk mata pelajaran matematika. Jika dilihat dari tabel nilai ulangan di atas masih banyak siswa yang belum tuntas, terlihat bahwa kemampuan siswa dalam menyelesaikan soal di bawah rata-rata. Lebih lanjut, guru memaparkan bahwa siswa kesulitan untuk memahami masalah kontekstual. Akibatnya, siswa kurang mampu memodelkan masalah tersebut dalam bentuk matematis. Siswa juga kurang terampil menginterpretasikan soal kontekstual dan siswa mengalami kesulitan dalam mengerjakan soal latihan yang sedikit berbeda dengan contoh soal yang diberikan oleh guru. Dapat disimpulkan kemampuan pemecahan masalah siswa SMP Negeri 6 Rengat masih tergolong rendah.

Berdasarkan permasalahan di atas perlu solusi yang tepat agar kemampuan pemecahan masalah matematis siswa lebih baik. Salah satu strategi pembelajaran yang diduga dapat meningkatkan kemampuan pemecahan masalah matematika siswa adalah strategi pembelajaran interaktif. Strategi pembelajaran interaktif menekankan pada diskusi dan sharing di antara peserta didik. Diskusi dan sharing memberi kesempatan peserta didik untuk berinteraksi terhadap gagasan, pengalaman, pendekatan dan pengetahuan guru atau temannya dan untuk membangun cara alternatif untuk berfikir dan merasakan. Disamping itu untuk mendukung proses diskusi dan sharing diperlukan teknik pembelajaran kolaboratif Send-A-Problem. Teknik pembelajaran kolaboratif Send-A-Problem setiap kelompok menerima sebuah masalah, mencoba menyelesaikannya, kemudian mengirimkan masalah tersebut dan solusinya kepada kelompok yang ada di sebelahnya. Selain itu, strategi pembelajaran interaktif dengan teknik pembelajaran kolaboratif SendA-Problem membuat siswa menjadi aktif, semangat dan dapat memberikan kesempatan kepada semua peserta didik untuk mengemukakan pendapatnya, dengan penggabungan strategi pembelajaran interaktif dan teknik pembelajaran kolaboratif Send-A-Problem dapat mengatasi rendahnya kemampuan pemecahan masalah matematis siswa. Dalam penelitian ini, peneliti melaksanakan strategi pembelajaran interaktif sesuai dengan tahap-tahap yang diungkapkan oleh Faire dan Cosgrove dalam Vaille dan Grady dimana dalam pelaksanaan tahap-tahapnya dipadukan dengan teknik pembelajaran kolaboratif send-a-problem. 


\section{METODE}

Penelitian ini menggunakan Quasi Experimental Design. Jenis penelitian ini digunakan karena merupakan pengembangan dari true experimental design, yang sulit dilaksanakan. Desain ini mempunyai kelompok kontrol, tetapi tidak dapat berfungsi sepenuhnya untuk mengontrol variabel-variabel luar yang mempengaruhi pelaksanaan eksperimen. Desain penelitian yang digunakan adalah Quasi Experimental Design dengan bentuk Randomized Subjects Posttest Only Control Group Design.

Tabel 2. Bentuk Randomized Subjects Postest Only Control Group Design

\begin{tabular}{cccc}
\hline & Group & Variabel Terikat & Posttest \\
\hline $\mathbf{R}$ & Eksperimental & $\mathrm{X}$ & $\mathrm{Y}_{2}$ \\
\hline $\mathbf{R}$ & Kontrol & - & $\mathrm{Y}_{2}$ \\
\hline
\end{tabular}

Keterangan:

$$
\begin{aligned}
& \mathrm{R}: \text { Random } \\
& \mathrm{X}: \text { Perlakuan } \\
& \mathrm{Y}_{2} \text { : Posttest }
\end{aligned}
$$

Populasi dalam penelitian ini adalah siswa kelas IX SMPN 6 Rengat yang memiliki 2 kelas yaitu kelas $\mathrm{IX}_{\mathrm{A}}$ dan $\mathrm{IX}_{\mathrm{B}}$ yang berjumlah 54 siswa sehingga sampel yang diambil pada penelitian ini adalah sampel total. Berdasarkan nilai ulangan kelas IX SMP Negeri 6 Rengat didapat bahwa rata-rata nilai kelas IX $_{\mathrm{A}}$ adalah 49,25 dan kelas IX $_{\mathrm{B}}$ adalah 45,5769. Dari data yang telah diperoleh tersebut maka terpilih kelas $\mathrm{IX}_{\mathrm{A}}$ sebagai kelas kontrol dan kelas $\mathrm{IX}_{\mathrm{B}}$ sebagai kelas eksperimen. Variabel bebas dalam penelitian ini adalah strategi pembelajaran interaktif dengan teknik pembelajaran send a problem, sedangkan variabel terikat yaitu kemampuan pemecahan masalah matematis siswa.

Instrument yang digunakan dalam penelitian ini adalah tes kemampuan pemecahan masalah matematis berupa tes berbentuk uraian yang terdiri dari 5 soal. Data kemampuan pemecahan masalah matematis siswa dianalisis menggunakan uji hipotesis, yaitu uji-t. Uji$\mathrm{t}$ dilakukan karena hasil tes akhir pada penelitian telah memenuhi uji prasyarat, yaitu uji normalitas dan uji homogenitas. Pengujian dilakukan dengan bantuan software SPSS 15.0.

\section{HASIL DAN PEMBAHASAN}

\section{Hasil}

Deskripsi data hasil tes kemampuan pemecahan masalah matematis siswa dapat dilihat pada tabel berikut.

Tabel 3. Hasil Perhitungan Data Kemampuan Pemecahan Masalah

\begin{tabular}{cccccc}
\hline Kelas & $\mathbf{N}$ & $\boldsymbol{\Sigma}$ & $\overline{\boldsymbol{x}}$ & $\boldsymbol{s}$ & $\boldsymbol{s}^{\mathbf{2}}$ \\
\hline Eksperimen & 26 & 1950 & 75 & 14.40486 & 207.500 \\
\hline Kontrol & 28 & 1802,5 & 64,375 & 19.45245 & 378.398 \\
\hline
\end{tabular}

Pada tabel 3 di atas terlihat bahwa rata-rata tes kemampuan pemecahan masalah matematis siswa kelas eksperimen lebih tinggi dari pada kelas kontrol. Sebaliknya, simpangan baku kelas eksperimen lebih rendah dibandingkan simpangan baku kelas kontrol. Penarikan kesimpulan dalam penelitian ini, dilakukan dengan uji hipotesis atau uji$\mathrm{t}$ secara statistik. Sebelum dilakukan uji-t terlebih dahulu dilakukan uji normalitas dan uji homogenitas.

\section{Uji Normalitas}

Uji normalitas dilakukan dengan cara Uji Liliefors. Uji Liliefors dilakukan bertujuan untuk melihat apakah sampel berdistribusi normal atau tidak. Hasil Perhitungan uji normalitas dapat dilihat pada Tabel berikut. 
Tabel 4. Hasil Uji Normalitas

\begin{tabular}{cccc}
\hline Sampel & Nilai Sig. & Nilai $\boldsymbol{\alpha}$ & Keterangan \\
\hline Eksperimen & 0,78 & 0,05 & Normal \\
\hline Kontrol & 0,63 & 0,05 & Normal \\
\hline
\end{tabular}

Dari Tabel di atas terlihat bahwa pada kelas eksperimen nilai Signifikan adalah 0,78 dan nilai signifikan untuk kelas kontrol adalah 0,63 karena nilai signifikan pada kedua kelas lebih besar dari $\alpha=0,05$ maka dapat disimpulkan bahwa kedua sampel berdistribusi normal.

\section{Uji Homogenitas}

Uji homogenitas di analisis dengan menggunakan uji homogenitas dua varians. Uji ini dilakukan untuk mengetahui populasi memiliki varians yang sama atau tidak. Hasil uji homogenitas kedua sampel dapat dilihat pada tabel berikut.

Tabel 5. Hasil Uji homogenitas

\begin{tabular}{cccc}
\hline Sampel & Nilai Sig. & Nilai $\alpha$ & Keterangan \\
\cline { 1 - 1 } Eksperimen & 0,112 & 0,05 & homogen \\
\hline
\end{tabular}

Dari Tabel di atas terlihat bahwa pada kelas sampel nilai Signifikan adalah 0,112 karena nilai signifikan lebih besar dari $\alpha=0,05$ maka dapat disimpulkan bahwa kedua sampel homogen.

\section{Uji Hipotesis}

Setelah pengujian normalitas dan homogen diperoleh hasil bahwa kedua sampel berdistribusi normal dan mempunyai varians homogen, maka dilakukan uji hipotesis dengan menggunakan (Uji t) Independent Samples T-Test dengan bantuan software SPSS. Berdasarkan hasil uji $t$ tersebut, diperoleh nilai $t_{\text {hitung }}=2,255$ dan didapat $\mathrm{t}_{\text {tabel }}=-2,310$ dengan (df) $\mathrm{n}-2$ dan taraf nyata $5 \%$. Karena nilai $\mathrm{t}_{\text {hitung }}>\mathrm{t}_{\text {tabel }}$, maka $\mathrm{H}_{0}$ ditolak. Sehingga dapat disimpulkan bahwa "Kemampuan Pemecahan Masalah Matematis Siswa dengan menggunakan Strategi Pembelajaran interaktif dengan teknik pembelajaran kolaboratif send a problem lebih baik dari pada Pembelajaran Konvensional di kelas IX SMP Negeri 6 Rengat".

\section{Pembahasan}

Dalam penelitian ini terdapat 4 indikator yang diukur peneliti, yaitu mengidentifikasi unsur yang diketahui, membuat model matematika, melaksanakan rencana pemecahan masalah menerapkan strategi menyelesaikan masalah, dan menjelaskan/ menginterprestasikan hasil.

a. Mengidentifikasi unsur yang diketahui.

Kemampuan mengidentifikasi unsur yang diketahui pada kelas eksperimen dan kelas kontrol ditinjau dari hasil tes kemampuan pemecahan masalah matematika siswa pada soal nomor 1 "Sebuah kerucut mempunyai diameter alasnya $18 \mathrm{~cm}$ dan panjang garis pelukis $15 \mathrm{~cm}$. Tentukan tinggi kerucut tersebut?”. Berdasarkan hasil jawaban siswa bahwa dalam menyelesaikan soal nomor 1 kelas kontrol memiliki perbedaan dengan kelas eksperimen.pada kelas control rata-rata siswa dalam menjawab soal nomor 1 langsung menuliskan jawabannya tanpa menuliskan unsur yang diketahui.

b. Membuat model matematika.

Kemampuan membuat model matematika pada kelas eksperimen dan kelas kontrol ditinjau dari hasil tes kemampuan pemecahan masalah matematika siswa pada soal nomor 2 "Sebuah pot bunga terbuat dari tanah liat berbentuk tabung. Jari-jari alas pot tersebut 
adalah $10 \mathrm{~cm}$ dan tingginya $20 \mathrm{~cm}$. jika pot bunga tanpa tutup tesebut akan dicat pada sisi samping dan alasnya, tentukan luas permukaan pot bunga yang akan dicat?". Berdasarkan hasil jawaban siswa dapat dilihat bahwa dalam menyelesaikan soal nomor 2 kelas kontrol memiliki perbedaan dengan kelas eksperimen. Pada kelas kontrol, dalam menjawab soal nomor 2 rata-rata siswa langsung menuliskan jawabannya tanpa membuat model matematisnya terlebih dahulu.

c. Melaksanakan rencana pemecahan masalah, menerapkan startegi menyelesaikan masalah, menyelesaikan model matematika dan masalah nyata.

Kemampuan Melaksanakan rencana pemecahan masalah menerapkan strategi menyelesaikan masalah, menyelesaikan model matematika dan masalah nyata pada kelas eksperimen ditinjau dari hasil tes kemampuan pemecahan masalah matematis siswa pada soal nomor 4 "Sebuah tabung memiliki ukuran jari-jari $14 \mathrm{~cm}$ dan tinggi $28 \mathrm{~cm}$. tabung tersebut berisi air setinggi $\frac{3}{4}$ bagian. Andi memasukkan 6 buah bola besi yang masingmasing memiliki jari-jari $7 \mathrm{~cm}$ hingga sebagian air tumpah dari tabung. Tentukan volume air yang tumpah dari dalam tabung?". Berdasarkan hasil jawaban, siswa kelas kontrol dalam menjawab soal siswa belum mampu melaksanakan rencana pemecahan masalah menerapkan strategi menyelesaikan masalah, menjelaskan serta menyelesaikan model matematika dan masalah nyata siswa langsung memberikan hasil saja.

\section{d. Menjelaskan/Menginterprestasikan Hasil}

Kemampuan menjelaskan/meninterprestasikan hasil pada kelas eksperimen ditinjau dari hasil tes kemampuan pemecahan masalah matematika siswa pada soal nomor 3 "Sebuah caping berbentuk kerucut dengan panjang garis pelukis $28 \mathrm{~cm}$. caping tersebut terbuat dari anyaman bambu seluas $1.232 \mathrm{~cm}^{2}$. Tentukan volume caping tersebut?" Berdasarkan hasil analisis jawaban tes kemampuan pemecahan masalah matematis siswa dari deskripsi tiap-tiap indikator yang dipilih maka diperoleh hasil bahwa kemampuan pemecahan masalah matematika kelas eksperimen lebih tinggi daripada kemampuan Pemecahan Masalah Matematis kelas kontrol. Hal ini juga sesuai dengan hipotesis pada penelitian ini, yaitu "Kemampuan pemecahan masalah matematis siswa dengan menggunakan Strategi Pembelajaran interaktif dengan teknik pembelajaran kolaboratif send a problem lebih baik dari pada kemampuan pemecahan masalah matematis siswa dengan menggunakan pembelajaran konvensional pada kelas IX SMP Negeri 6 Rengat".

Secara umum, melalui hasil analisis jawaban tes kemampuan pemecahan masalah matematika siswa dari deskripsi tiap-tiap indikator yang dipilih maka dapat disimpulkan bahwa kemampuan pemecahan masalah matematis siswa kelas IX SMP Negeri 6 Rengat berada pada kriteria level keempat (4) dimana siswa dalam memberikan jawaban dengan jelas dan lengkap, penjelasan atau deskripsi tidak ambigu (bermakna ganda); dapat memasukkan suatu rumus yang tepat dan lengkap; mengkomunikasikan secara efektif kepada audien; mengajukan argumen pendukung yang kuat dan dapat diterima secara logis.

\section{KESIMPULAN}

Berdasarkan hasil penelitian dan pembahasan dapat disimpulkan bahwa kemampuan pemecahan masalah matematis siswa dengan penerapan strategi pembelajaran interaktif dengan teknik pembelajaran kolaboratif send-a-problem lebih baik daripada pembelajaran konvensional pada siswa kelas IX SMP Negeri 6 Rengat. Berdasarkan hasil penelitian tersebut disarankan kepada guru bidang studi matematika untuk dapat menjadikan strategi pembelajaran interaktif dengan teknik pembelajaran send a problem sebagai salah satu variasi dalam menggunakan strategi pembelajaran untuk meningkatkan kemampuan 
pemecahan masalah matematis siswa di sekolah baik pada mata pelajaran matematika atau mata pelajaran lainnya.

\section{DAFTAR PUSTAKA}

Majid, A. 2013. Strategi Pembelajaran. Bandung: PT Remaja Rosdakarya Offfset.

Elizabert E., Barkley, K., Cross, P., \& Major, C. W. 2012. Collaborative Learning Techniques. Bandung: Nusa Media.

Uno, H. B. 2014. Model Pembelajaran. Jakarta: Bumi Aksara.

Husnah, M.Ikhsan, Siti Fatimah. 2013. Peningkatan kemampuan pemecahan masalah dan komunikasi matematis siswa sekolah menengah pertama melalui model pembelajaran kooperatif tipe think-pair-share (tps). Jurnal ISSN:2302-5158. 1(2): 81-92.

Ngalimun, 2012. Strategi dan Model Pembelajaran. Yogyakarta: Aswaja Pressindo. Sugiono, 2011. Metode Penelitian Kuantitatif Kualitatif dan R\&B. Bandung: Alfabeta. Sanjaya, W. 2006. Strategi Pembelajaran. Jakarta: Kencana Prenadamedia Group.

Susanti, W, Nofrianto, A \& Amri, M. A. 2016. Peningkatan Kemampuan Pemecahan Masalah Matematika Siswa Melalui Model Pembelajaran Laps-Heuristic Dikelas X SMAN 2 Batang Anai. Jurnal Gantang Pendidkan Matematika FKIP-UMRAH, 1(2): 39-50. 